\title{
Influence of the anodization conditions and chemical treatment on the formation of alumina membranes with defined pore diameters
}

\author{
Iwona Dobosz ${ }^{1}$ (D)
}

Accepted: 12 February 2021 / Published online: 3 March 2021

(c) The Author(s) 2021

\begin{abstract}
Porous anodic aluminum oxide membranes were fabricated via two-step anodization of aluminum in $0.3 \mathrm{M} \mathrm{H}_{2} \mathrm{C}_{2} \mathrm{O}_{4}, 0.3 \mathrm{M}$ $\mathrm{H}_{2} \mathrm{SO}_{4}$ and $0.17 \mathrm{M} \mathrm{H}_{3} \mathrm{PO}_{4}$ solutions. The parameters of the oxide film such as: pore diameter $\left(\mathrm{D}_{\mathrm{p}}\right)$, interpore distance $\left(\mathrm{D}_{\mathrm{c}}\right)$, porosity $(\mathrm{P})$ and pore density $(\rho)$ can be completely controlled by the operating conditions of the anodization. Additionally, the pore diameters and pore density can be controlled via a chemical treatment (pore opening/widening process). The effect of anodizing conditions such as the applied voltage, type of electrolyte and purity of the substrate on the rate of porous oxide growth are discussed. The obtained results were compared with the theoretical predictions and data that has been reported in the literature. The influence of the duration of chemical etching on the structural features of the oxide membranes was studied. On the based on qualitative and quantitative FFT analyzes and circularity maps, it was found that the nanostructures of anodized aluminum have the maximum order under certain specified conditions. The presence of alloying elements affects not only the rate of oxide growth but also the morphology of the anodic aluminum oxide. The rate of oxide growth depends on the electrolyte type and temperature. During chemical treatment of the oxide films pore diameter increases with the pore widening time and the highest pore widening was observed in phosphoric acid solution.
\end{abstract}

Keywords Porous aluminum oxide $\cdot$ Anodizing $\cdot$ Pore widening $\cdot$ Self-organization

\section{Introduction}

Recently, many research groups have been intensively working on fabricating various nanostructured materials such as nanowires [1-5], nanotubes [6-9] and nanodots [10-12] that have new properties compared to the bulk materials. These nanostructures could have many potential applications in various fields of science such as medicine (oncology) [13], renewable energy, catalysis [14], electronics and in sensors $[15,16]$. In particular, anodic aluminum oxide (AAO) has attracted much interest due to the regular arrangement of its nanopore structures, ease of controlling the nanopore diameters, large surface area, low fabrication costs, excellent thermal stability, non-toxicity and biocompatibility [17]. These highly ordered AAO arrays can be achieved by using lithographic techniques $[18,19]$ or self-organization

Iwona Dobosz

iwona.dobosz@agh.edu.pl

1 Faculty of Non-Ferrous Metals, AGH University of Science and Technology, 30 Mickiewicza Ave, 30-059 Cracow, Poland methods [20,21]. In the lithographic techniques, aluminum is directly pre-textured and then anodized to obtain porous structures free of defects. However, such a method has two disadvantages, i.e.: the high cost of manufacturing and the limited working area [22]. Although the self-organization method enables a highly ordered structure to be obtained over a relatively large surface area with low manufacturing cost, the alumina is not free of defects. Anodic aluminum oxide which has hexagonally arranged pores, is usually obtained via the self-organized two-step potentiostatic or galvanostatic anodization of aluminum in acidic electrolytes [23, 24]. In this process, after the first anodization step, aluminum oxide is chemically removed and the $\mathrm{Al}$ substrate with concaves is re-anodized. Many researchers have studied the preparation, morphology and structure of the oxide film on aluminum. Keller et al. [25] described porous alumina as a double structure consisting of porous and barrier layers and showed the formation of a porous alumina layer that had hexagonal cells with nanopores at their centres. At the bottom of the pores, a continuous and dielectric oxide layer was built that was called the barrier layer. Wood et al. [24] conducted research on the anodic oxide films for two decades 
and their paper on the anodization of aluminum to obtain porous alumina structures, which was published in 1970 by O'Sullivan and Wood, is one of the most cited papers. Further, Masuda and Fukuda developed a multi-step anodization technique to improve the periodicity of the porous structure of AAO [23, 26].

Anodic porous alumina, which is produced by the selforganization process of mild anodization, is characterized by a uniform pore structure that is suitable for nanotechnological applications. Such materials are usually obtained by a voltage-controlled two-step anodization in sulfuric [20, 21, 27], oxalic [28-31] and phosphoric [26, 28, 32] acid solutions. Other electrolytes such as tartaric acid, citric acid or malonic acid can also be used but their use is rather infrequent $[33,34]$. The best nanopore arrangement in a selforganized alumina membrane is observed at the optimal value of the anodizing voltages for the individual acids. It was found that at anodizing voltages below the designated range, low-ordered nanostructures are produced, while at the higher voltages, there is always a breakdown or burning of the oxide film due to destructive flow of electric current coupled with the large amount of reaction heat. The interpore distance of anodic alumina oxide is linearly dependent on the applied voltage and has a proportionality constant of about $2.5 \mathrm{nmV}^{-1}$ regardless of the electrolyte that is used for the anodization [28]. Some literature data uses the term "anodizing potential" when referring to the anodizing process [27, 28, 30, 35]. However, the potential in chemistry or electrochemistry, according to the IUPAC definition, is the electromotive force of a cell consisting of two electrodes: there is a standard hydrogen electrode (SHE) on the left side of the cell diagram, while the electrode in question is on the right side. Therefore term "anodizing voltage" is more appropriate [15, 36-38]. The anodic alumina that is produced via the typical industrial process of hard anodization is characterized by non-uniform pore structures and numerous defects. The hard anodization process applies high current densities that are usually one or two orders of magnitude higher than a mild anodization. This results in a 25 to 35 times faster alumina growth during hard anodization.

In this paper was reported how the anodizing temperature and voltage affected on both the structural features and pore arrangement of alumina oxide layer formed in three different acid solutions. The anodization of high purity aluminum foil in sulfuric, oxalic and phosphoric acids at different voltages and temperatures is presented. For comparison, the anodization of an AA 1050 aluminum alloy in oxalic acid solution was also performed. Here for the first time, the influence of the duration of chemical etching on the pore diameter and pore density of the oxide membranes was studied. A special emphasis is put on the quantitative and qualitative analyses of hexagonal arrangement of pore arrays. Therefore, qualitative and quantitative analyses of the pore arrangement were performed and the fast Fourier Transformation (FFT) images are presented.

\section{Experimental}

Two aluminum materials of different purities were used as the substrates. These were a high purity $0.3 \mathrm{~mm}$ thick annealed aluminum foil (99.999\%; Alfa-Aesar) and an annealed AA1050 alloy (min. 99.5\% Al). The AA1050 alloy contained iron $(<0.3 \%)$ and silicon $(<0.2 \%)$ as principal alloying elements. The substrates were cut to obtain samples with a working surface of $0.8 \mathrm{~cm}^{2}$.

Firstly, the samples were degreased ultrasonically in acetone and ethanol for $3 \mathrm{~min}$. Then, they were polished electrochemically using an electropolisher (Stuers LectroPol-5). A mixture of $60 \% \mathrm{HClO}_{4}$ and $96 \% \mathrm{C}_{2} \mathrm{H}_{5} \mathrm{OH}$ (1:4 volume ratio) with methylcellulose added to increase the solution viscosity, constant voltage of $48 \mathrm{~V}$, a polishing time of $20 \mathrm{~s}$ and a temperature of $16{ }^{\circ} \mathrm{C}$ were used [5].

Self-ordered porous aluminum oxide was formed via two-step anodization at a constant cell voltage. The detailed anodizing conditions are summarized in Table 1.

The oxide layer that formed on the $\mathrm{Al}$ substrate during the first anodization was chemically removed by chemical etching in a mixture of $6 \mathrm{wt} \% \mathrm{H}_{3} \mathrm{PO}_{4}$ and $1.8 \mathrm{wt} \% \mathrm{H}_{2} \mathrm{CrO}_{4}$ at $80{ }^{\circ} \mathrm{C}$. After the oxide was removed, the samples were re-anodized in the same conditions as in the first step. The $\mathrm{Al}$ substrate was removed to produce the AAO membrane. This was performed by immersing oxidized substrate in a mixture of $18.2 \% \mathrm{HCl}$ and $3.3 \% \mathrm{CuCl}_{2}$ solutions (1:3) at a room temperature. After this process, the pores were opened. The barrier layer of the oxide film was etched in a $5 \mathrm{wt} \%$ $\mathrm{H}_{3} \mathrm{PO}_{4}$ solution at $30^{\circ} \mathrm{C}$. Membranes with different pore diameters were obtained by monitoring the duration of the pore opening/widening process. The working conditions that were used for the pore widening are summarized in Table 1.

The sample morphology was determined using an FE Gemini LEO 1530 field emission scanning electron microscope (FE-SEM). The design features of the alumina membranes, i.e.: the pore diameter $\left(D_{p}\right)$, interpore distance $\left(D_{c}\right)$, porosity $(\delta)$, pore density $(\mathrm{P})$ and oxide layer thickness $(\mathrm{h})$ were evaluated based on the FE-SEM images using a WSxM v. 12.0 image processor [39] and ImageJ software [40].

\section{Results and discussion}

Figure 1 shows the current-time transients that were recorded during the second anodization step, which was performed in $0.3 \mathrm{M}$ sulfuric acid for an anodizing voltage ranging from 15 to $30 \mathrm{~V}$ (Fig. 1a) and in $0.3 \mathrm{M}$ oxalic acid for an anodizing voltage ranging from 30 to $60 \mathrm{~V}$ (Fig. 1b). 
Table 1 Experimental conditions applied during anodization and the structural features of the nanoporous alumina membranes

\begin{tabular}{|c|c|c|c|c|c|c|c|c|c|c|c|}
\hline \multirow[t]{2}{*}{ Starting material } & \multicolumn{5}{|c|}{ Anodizing parameters } & \multirow[b]{2}{*}{$\mathrm{D}_{\mathrm{p}}(\mathrm{nm})$} & \multicolumn{5}{|c|}{ Characteristic membrane parameters } \\
\hline & Electrolyte & $\mathrm{U}(\mathrm{V})$ & $\mathrm{T}\left({ }^{\circ} \mathrm{C}\right)$ & $\mathrm{t}_{1} / \mathrm{t}_{2}(\mathrm{~h})$ & $\lambda \mathrm{p}$ & & $\lambda \mathrm{c}$ & $\mathrm{D}_{\mathrm{c}}(\mathrm{nm})$ & $\mathrm{h}(\mu \mathrm{m})$ & $\mathrm{P}\left(\mathrm{cm}^{-2}\right)$ & $\delta(\%)$ \\
\hline \multirow[t]{4}{*}{ Al 99,999\% } & \multirow[t]{4}{*}{$0.3 \mathrm{M} \mathrm{H}_{2} \mathrm{SO}_{4}$} & 15 & \multirow[t]{5}{*}{$1 / 8^{*}$} & \multirow[t]{4}{*}{$24 / 3$} & 0.66 & $10 \pm 3$ & 2.90 & $44 \pm 5$ & \multirow[t]{5}{*}{$29 / 50^{*}$} & $5.96 \times 10^{10}$ & 4.7 \\
\hline & & 20 & & & 0.85 & $17 \pm 3$ & 3.20 & $62 \pm 6$ & & $3.00 \times 10^{10}$ & 6.8 \\
\hline & & 25 & & & 0.84 & $21 \pm 3$ & 2.64 & $66 \pm 4$ & & $2.65 \times 10^{10}$ & 9.2 \\
\hline & & 30 & & & 0.56 & $17 \pm 8$ & 2.43 & $73 \pm 14$ & & $2.16 \times 10^{10}$ & 4.9 \\
\hline \multirow[t]{4}{*}{ Al 99,999\% } & \multirow[t]{4}{*}{$0.3 \mathrm{M} \mathrm{H}_{2} \mathrm{C}_{2} \mathrm{O}_{4}$} & 30 & & & 0.60 & $18 \pm 6$ & 2.76 & $83 \pm 7$ & & $1.68 \times 10^{10}$ & 4.3 \\
\hline & & 40 & \multirow[t]{3}{*}{$2 / 8^{*}$} & \multirow[t]{3}{*}{$24 / 6$} & 0.67 & $27 \pm 3$ & 2.47 & $99 \pm 8$ & \multirow[t]{3}{*}{$20 / 26^{*}$} & $1.18 \times 10^{10}$ & 6.7 \\
\hline & & 50 & & & 0.67 & $31 \pm 6$ & 2.60 & $130 \pm 7$ & & $6.83 \times 10^{9}$ & 5.2 \\
\hline & & 60 & & & 0.66 & $40 \pm 14$ & 2.43 & $146 \pm 12$ & & $5.42 \times 10^{9}$ & 6.8 \\
\hline \multirow{6}{*}{$\begin{array}{l}\text { Al } 1050 \\
\text { Al 99,999\% }\end{array}$} & $0.3 \mathrm{M} \mathrm{H}_{2} \mathrm{C}_{2} \mathrm{O}_{4}$ & 40 & \multirow[t]{4}{*}{2} & \multirow[t]{4}{*}{$24 / 6$} & 0.55 & $22 \pm 4$ & 2.65 & $103 \pm 13$ & \multirow[t]{4}{*}{14} & $1.03 \times 10^{10}$ & 4.1 \\
\hline & $0.17 \mathrm{M} \mathrm{H}_{3} \mathrm{PO}_{4}$ & 120 & & & 0.78 & $94 \pm 29$ & 2.40 & $288 \pm 2$ & & $1.39 \times 10^{9}$ & 9.6 \\
\hline & & 140 & & & 0.55 & $77 \pm 32$ & 2.19 & $307 \pm 50$ & & $1.22 \times 10^{9}$ & 5.7 \\
\hline & & 160 & & & 0.32 & $52 \pm 17$ & 1.07 & $171+99$ & & $3.94 \times 10^{9}$ & 8.4 \\
\hline & & 180 & \multirow[t]{2}{*}{$-1 / 3^{*}$} & \multirow[t]{2}{*}{$2 / 10$} & 0.61 & $111 \pm 42$ & 2.36 & $425 \pm 98$ & \multirow[t]{2}{*}{$16 / 29 *$} & $6.39 \times 10^{8}$ & 6.2 \\
\hline & & 200 & & & 0.60 & $121 \pm 83$ & 2.39 & $478 \pm 94$ & & $5.05 \times 10^{8}$ & 5.8 \\
\hline
\end{tabular}

$\mathrm{U}$-anodizing voltage, $\mathrm{t}_{1}$ and $\mathrm{t}_{2}$ - time of the first and second anodization steps, $\mathrm{T}$ - temperature, $\mathrm{D}_{\mathrm{p}}$ - pore diameter, $\mathrm{D}_{\mathrm{c}}$-interpore distance, $\mathrm{h}$ - oxide layer thickness, $\mathrm{P}$ - pore density, $\delta$ - porosity, $\lambda \mathrm{p}$ - proportionality constants calculated from Eq. (1), $\lambda \mathrm{c}-$ proportionality constants calculated from Eq. (2)

*Higher temperature

Fig. 1 Current density vs. anodizing time that was recoded for various anodizing voltages during the first $60 \mathrm{~min}$ of the second anodization step. The anodization process was performed in: a $0.3 \mathrm{M} \mathrm{H}_{2} \mathrm{SO}_{4}, 1^{\circ} \mathrm{C}$ and b $0.3 \mathrm{M} \mathrm{H}_{2} \mathrm{C}_{2} \mathrm{O}_{4}, 2{ }^{\circ} \mathrm{C}$
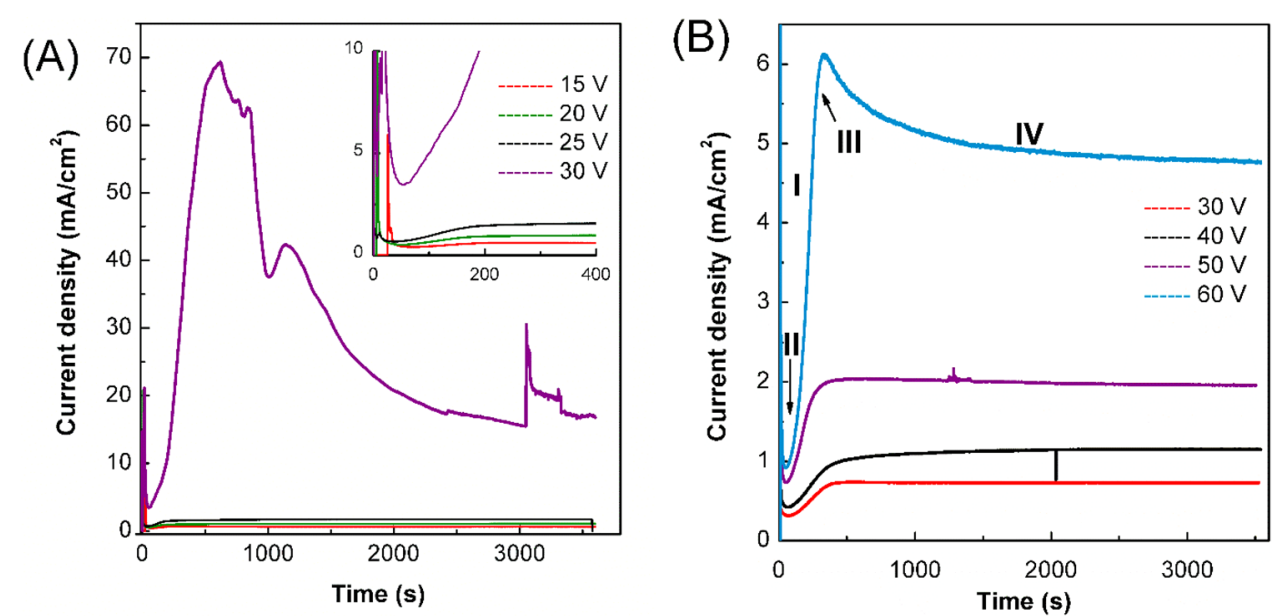

During the first stage of the anodization, the current density decreased rapidly with time due to the formation of a compact, high-resistant oxide film (i.e. barrier layer) on the aluminum substrate (stage I marked in Fig. 1b). Next, at the minimum of the current density, individual pathways through the barrier layer were generated and then the pore precursors were formed, which caused the current density to increase (II). During the next stage, the reconstructed pores were visible on the current-time curves as the local maximum (III). This was followed by the growth of a porous oxide layer that corresponded with the constant current density in time (IV). It was observed that an increasing voltage enabled higher current densities to be generated. However, when the anodizing voltage was more than $25 \mathrm{~V}$ for sulfuric acid solution, high current was accompanied by an intense gas evolution on the entire sample surface. This was associated with the disordered growth of the pores in an uncontrolled manner. For the oxalic acid solution, there was a similar behavior at high currents at $50 \mathrm{~V}$ (Fig. 1b). Ono et al. [38] revealed that the electronic current that is caused by the electric breakdown of the barrier layer due to an intense gas evolution is preferential to an ionic current. The opposite effect was observed for the phosphoric acid solution in which the thickening of the local layer was observed at $200 \mathrm{~V}$. This was accompanied by the flow of high anodic currents 
and a phenomenon that is commonly called "burning". Moreover, a longer stabilization and fluctuations on the current-time curves at a high anodizing voltage can be explained by the excessive heating of the electrolyte, which can lead to the secondary local dissolution of the oxide layer and damage to the pore walls. At high anodizing voltages, the chemical dissolution rate at the oxide/ solution interface as well as the Joule heat increases [36].

The influence of anodization voltage on the nanostructures that formed in sulfuric acid was investigated via the qualitative (SEM) and quantitative (FFT) analyzes of the regularity of the pore arrangement. The Fourier transform gives helpful information about the periodicity of a structure. For an ideal triangular lattice with a hexagonal pore arrangement, the FFT pattern consists of six distinct spots on the edges of a hexagon as is shown in Fig. 2c. In addition, the visible points on the second circle indicate an ordering of 1 st and 2 nd degrees, which means a regularity of the pore diameter and wall thickness (the example in Fig. 2c). The occurrence of any disturbances in the lattice order results in a ring-shaped or even disk-shaped form in the FFT image (non-ideal structure) as is shown in Fig. 2a. Moreover, as the pore diameter increases, the visible points form a smaller ring.
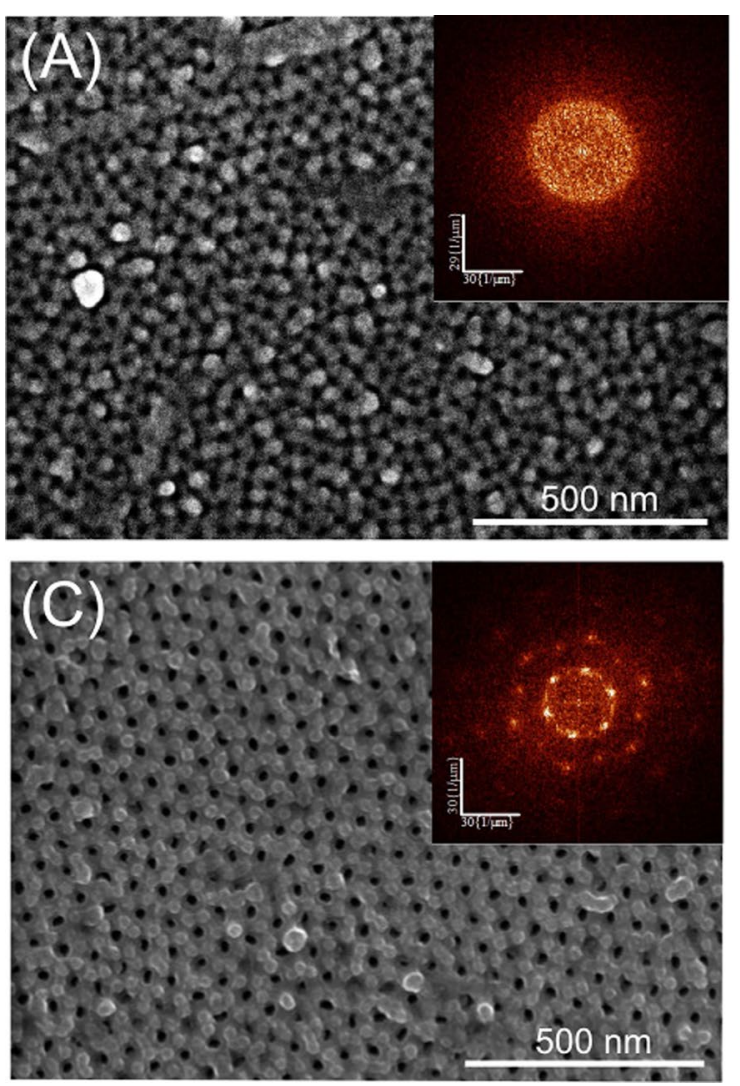

Figures 2, 3, and 4 present the typical top view of the SEM images and FFT of the nanoporous alumina that was produced under various anodization voltages in the acid solutions. It was found that for $\mathrm{H}_{2} \mathrm{SO}_{4}$ at $1{ }^{\circ} \mathrm{C}$, the best arrangement was obtained for a voltage of $25 \mathrm{~V}$. The FFT image showed six distinct dots at the edges of the hexagon, which confirmed a good arrangement of the nanopores (Fig. 2c). Above $25 \mathrm{~V}$, there was a decrease in and regularity of the arrangement and the occurrence of oval-shaped pores (Fig. 2d). In turn, for voltages lower than $25 \mathrm{~V}$, the dots in the FFT image were not so distinct (a less circular shape of the pores Fig. 2a, b) and the FFT image even had a disk-shape pattern, which indicated much less regularity of the pore arrangement. There was no second ring in the FFT image for a voltage of $15 \mathrm{~V}$, which indicates a variable wall thickness or a variable pore diameter (less circular shape of the pores Fig. 2a).

Figure 3 shows the SEM images and FFT of the nanostructures that formed in the oxalic acid solution at $2{ }^{\circ} \mathrm{C}$ under anodizing voltages of $30-60 \mathrm{~V}$. The pores on the surface that are presented in Fig. 3a were distributed relatively regularly but the well-ordered domains with an excellent arrangement of the nanoholes was rather small. As a result, the ring shape in FFT image indicated a relatively
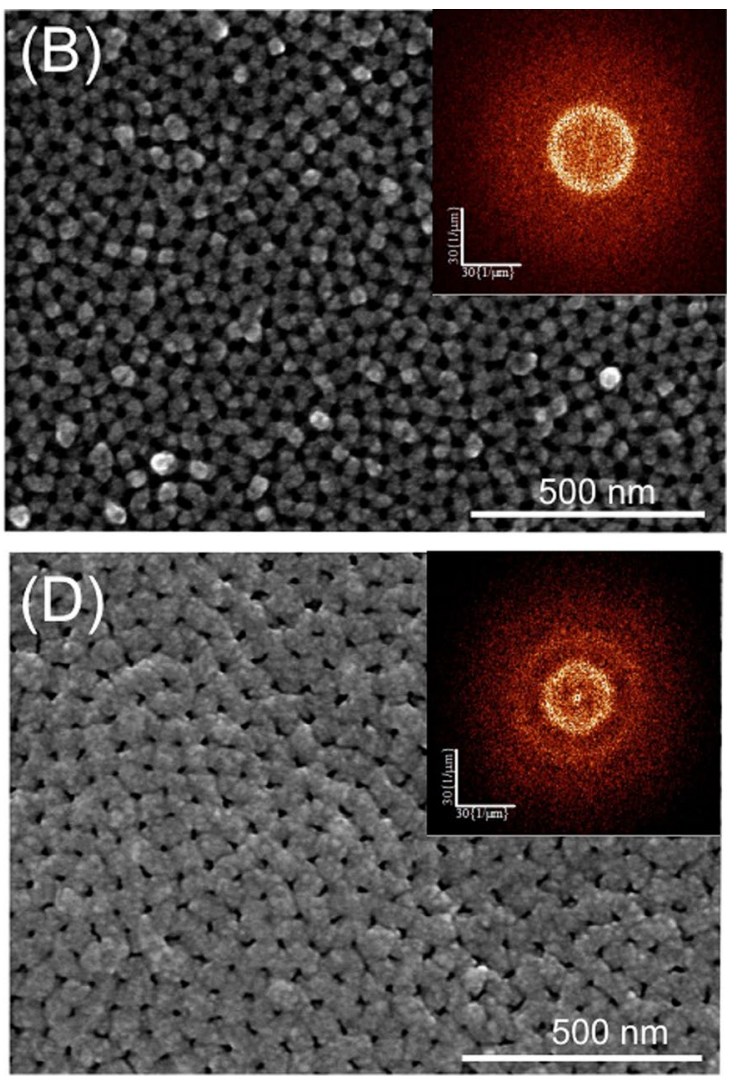

Fig. 2 SEM top view images with their FFT images of the porous alumina after the second anodization step in the $0.3 \mathrm{M}$ sulfuric acid solution at $1{ }^{\circ} \mathrm{C}$ under anodizing voltages of $15(\mathbf{a}), 20(\mathbf{b}), 25(\mathbf{c})$ and $30 \mathrm{~V}(\mathbf{d})$. The duration of each anodization step was $2 \mathrm{~h}$ 

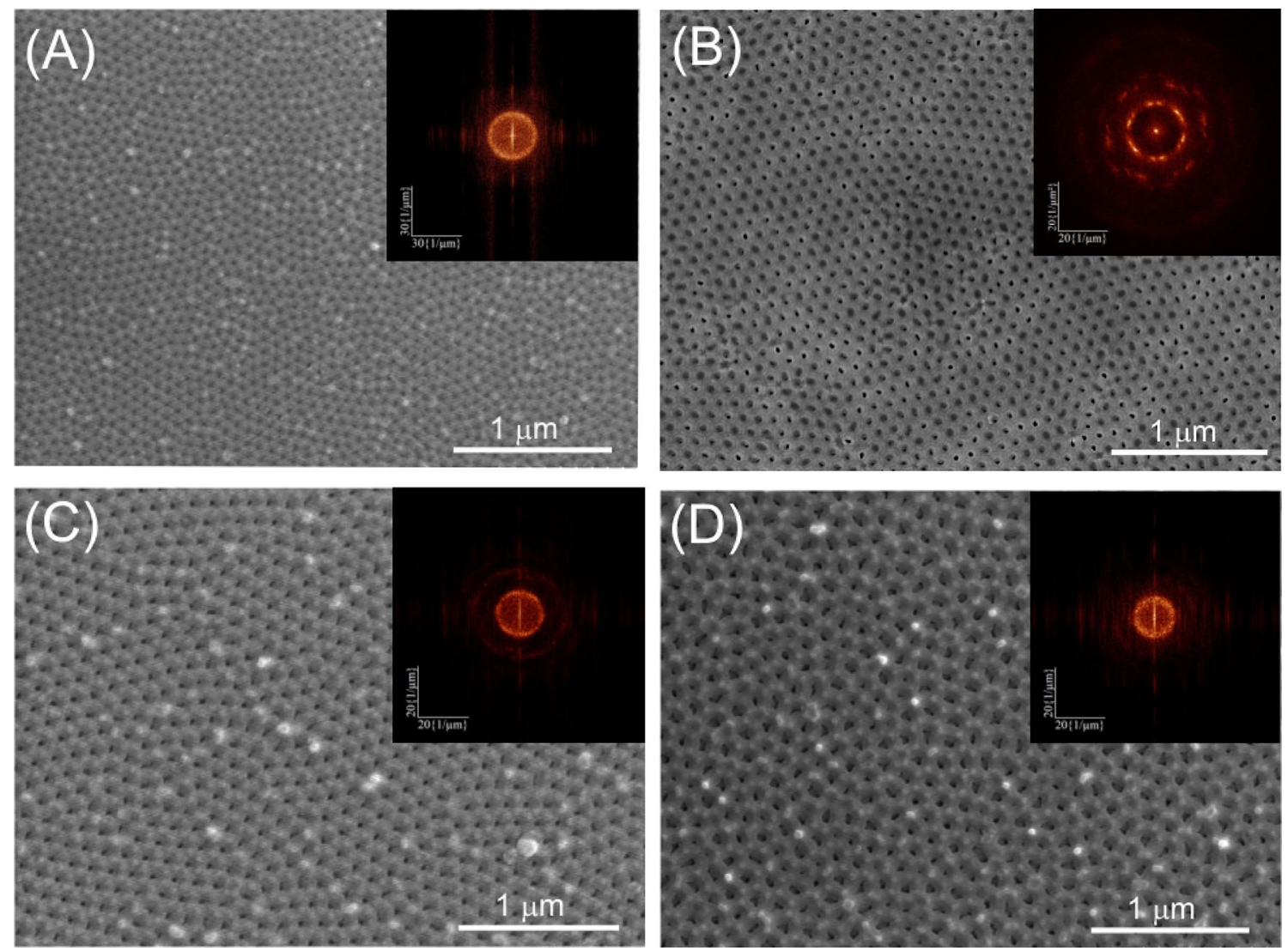

Fig. 3 SEM top view images with their FFT images of the porous alumina after the second anodization step in the $0.3 \mathrm{M}$ oxalic acid solution at $2{ }^{\circ} \mathrm{C}$ under anodizing voltages of $30(\mathbf{a}), 40(\mathbf{b}), 50$ (c) and $60 \mathrm{~V}(\mathbf{d})$. The duration of each step was $2 \mathrm{~h}$

large number of domains that did not have sharp boundaries between them. The best arrangement of the nanopores was obtained for $40 \mathrm{~V}$ for which the FFT image consisted of six distinct dots at the edges of the hexagon (Fig. 3b). For an anodizing voltage of $50 \mathrm{~V}$, the narrow ring structure with six more noticeable intensive patterns in the FFT image indicated a less circular shape of the pores and a decrease in the regularity of the arrangement (Fig. 3c). For voltages higher than $50 \mathrm{~V}$, the dots in the FFT image were not so distinct (less round shape of the pores in Fig. 3d) or the FFT image was even a disk-shape pattern, thus indicating a lesser regularity of the pore arrangement.

A random arrangement of pores and lack of uniformity in the pore diameter and pore shape were observed in the $\mathrm{H}_{3} \mathrm{PO}_{4}$ for all of the anodizing voltages (120-200 V). This fact was confirmed by the wide ring shapes in the FFT images (Fig. 4). At a voltage of $120 \mathrm{~V}$, the FFT image showed a blurry disk-shape pattern, which indicated a low regularity of the distribution of the pores (Fig. 4a). Furthermore, there was no uniformity in the diameters and shapes of the pores. With an increasing anodizing voltage, the pore diameters increase gradually. For anodizing under $140 \mathrm{~V}$ and $160 \mathrm{~V}$, there was a disorderly distribution of the pores and a less round pore shape (Fig. 4b, c), which was confirmed by the elongated ring-shape of the pores in the FFT images. Moreover, with an increasing anodizing voltage of up to $180 \mathrm{~V}$, the regularity of the pore arrangement and their roundness increased, but the perfectly circular pore shape was not been achieved as had been expected (Fig. 4d). Above $180 \mathrm{~V}$, the porous anodic alumina films exhibited a complex structure with sub-pores that had formed beneath the surface (Fig. 4e).

Figure 5 shows the SEM micrographs for the samples obtained by the anodization of AA1050 alloy (Fig. 5a and b) and high purity aluminum (Fig. 5c and d) in the oxalic acid. The anodization of pure aluminum (99.999\%) resulted in the formation of a nanoporous alumina layer that had an almost ideal, hexagonal arrangement of the pores. It was clearly visible that the two-step anodization of the AA1050 alloy resulted in the formation of alumina layers that had a worse pore arrangement and many defects in the hexagonal assembly of the pores had been generated. These defects were also visible on a cross-section of the oxide film. This means that the structures that were obtained via the anodization of the high purity aluminum had a perfect hexagonal arrangement of the pores. 

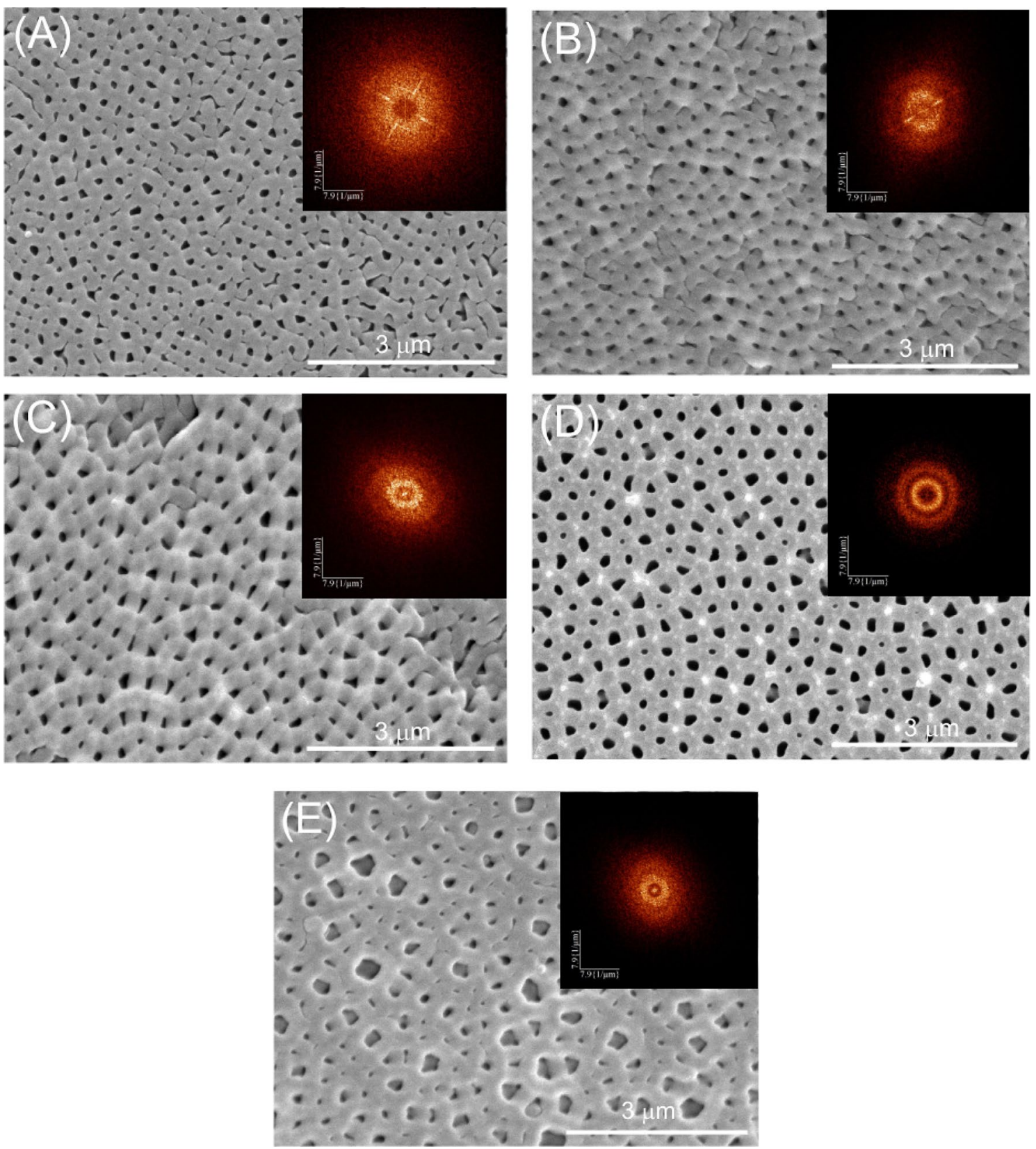

Fig. 4 SEM top view images with their FFT images of the porous alumina after the second anodization step in the $0.17 \mathrm{M}$ phosphoric acid solution at $-1{ }^{\circ} \mathrm{C}$ under anodizing voltages of $120(\mathbf{a}), 140(\mathbf{b}), 160(\mathbf{c}), 180(\mathbf{d})$ and $200 \mathrm{~V}(\mathbf{e})$. The duration of each step was $2 \mathrm{~h}$

Alloying elements such as $\mathrm{Si}, \mathrm{Mg}, \mathrm{Fe}, \mathrm{Mn}$ and $\mathrm{Cu}$ cause defects in the porous alumina structure.

An important parameter is the anodizing voltage. For the process that was performed in $0.3 \mathrm{M} \mathrm{H}_{2} \mathrm{SO}_{4}$ at $1{ }^{\circ} \mathrm{C}$, an increase in the applied voltage from 15 to $30 \mathrm{~V}$ resulted in a significant increase in the growth rate of the alumina layer. Simultaneously, the higher applied voltage also increased the pore diameter $\left(D_{p}\right)$ and interpore distance $\left(D_{c}\right)$ but worsened the regularity of the nanopore arrangement. These observations are also confirmed by other studies $[38,41]$.
The average pore diameter was calculated for various electrolytes using ImageJ software [40], however, it should be noted that estimating the pore diameters from the SEM images was especially difficult for the samples that had been fabricated via the anodization in the phosphoric acid solution and the AA1050 alloy in the oxalic acid solution due to the low uniformity of the pore shapes.

In accordance with Eq. (1): 

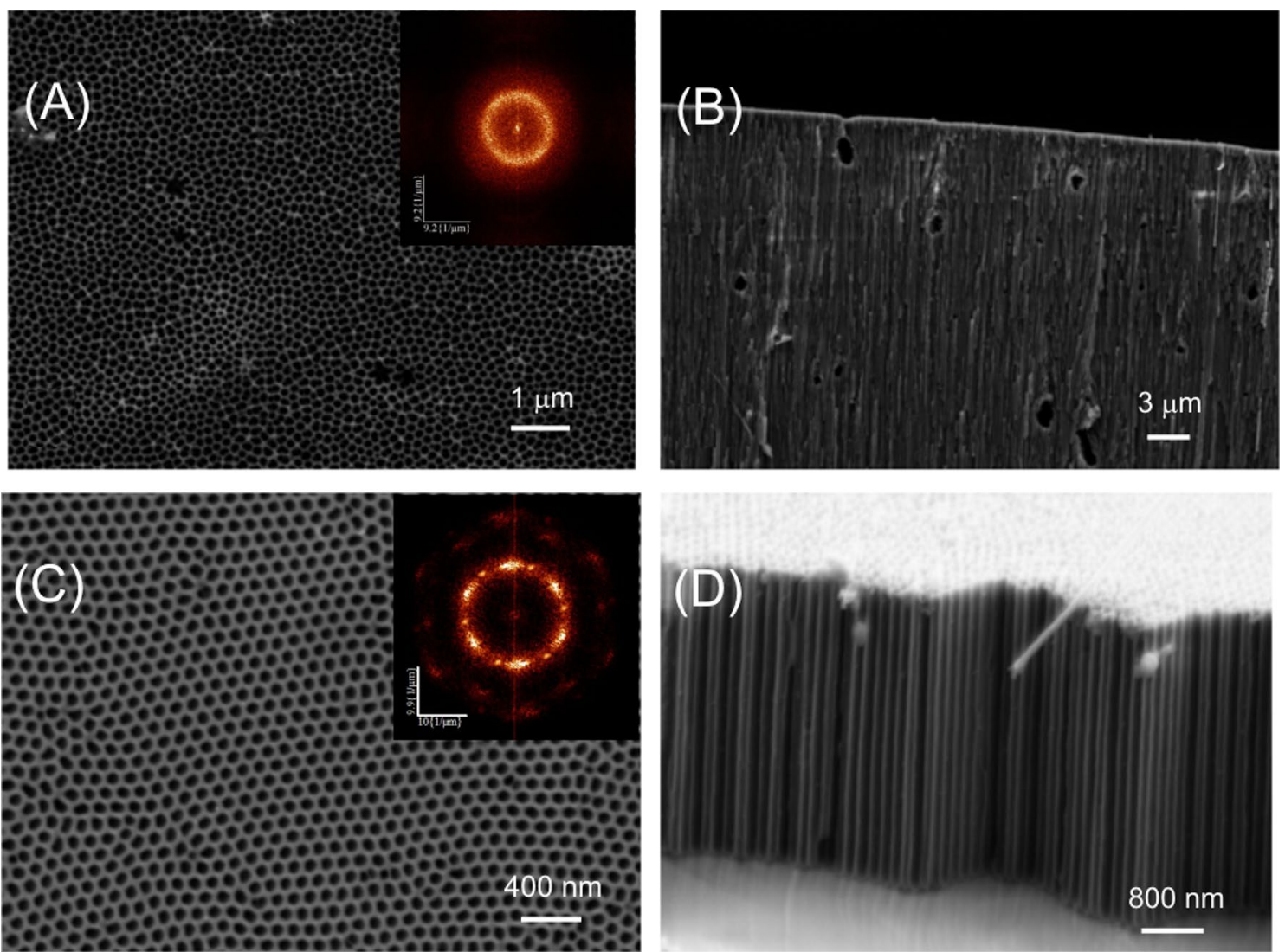

Fig. 5 SEM top view $(\mathbf{a}, \mathbf{c})$ and cross section $(\mathbf{b}, \mathbf{d})$ images of the porous alumina after the second anodization step in the 0.3 oxalic acid solution under $40 \mathrm{~V}$ on the AA1050 aluminum alloy (a, b) and high purity $\mathrm{Al}(\mathbf{c}, \mathbf{d})$

$\mathrm{D}_{\mathrm{p}}=\lambda_{\mathrm{p}} \mathrm{U}$

the anodization that had been performed in the oxalic acid and phosphoric acid solutions resulted in larger pore diameters than those in the sulfuric acid at a lower anodizing voltage where $\lambda$ p is proportionality constant and $\mathrm{U}$-anodizing voltage. It should be noted, that pore diameter is strongly dependent on both on applied anodizing voltage, but also on the type and concentration of the electrolyte.

The average interpore distance of the porous structures (Eq. 2)

$\mathrm{D}_{\mathrm{c}}=\lambda_{\mathrm{c}} \mathrm{U}$

Along with the $\lambda c$ proportionality constant are presented in Table 1. As can be seen from Table 1 the structural features, such as pore diameter, interpore distance, porosity and pore density of porous anodic alumina formed on AA1050 are a little different from those obtained for high purity Al. The pore diameter and the rate of oxide growth of AAO membranes formed from the AA1050 alloy were a bit smaller from those obtained for a high purity $\mathrm{Al}$ foil. Whereas the observed values of interpore distance and standard deviation were slightly higher for anodizing of the AA1050 alloy than those for anodic films on high purity Al.

The porous alumina layer is often characterized by its porosity $(\delta)$ and pore density $(\mathrm{P})$, which are given by Eqs. (3) and (4), respectively. Porosity is defined as the ratio of the surface area that is occupied by the pores to the entire surface area of a sample. Equation 3:

$\delta=\frac{\pi}{2 \sqrt{3}} \times\left(\frac{D_{p}}{D_{c}}\right)^{2}=0.907 \times\left(\frac{D_{p}}{D_{c}}\right)^{2}$

shows that porosity is inextricably correlated with both the pore diameter and the distance between the pores. Moreover, for a perfect hexagonal arrangement of the nanopores that are formed under optimum anodizing conditions, the porosity should be about $10 \%$ [28].

For the hexagonal pore arrangement, the pore density, which is defined as the total number of pores per $1 \mu \mathrm{m}^{2}$ of the surface area, is inversely proportional to the square of the anodizing voltage. 
$P=\frac{2 \cdot 10^{14}}{\sqrt{3} \cdot D_{c}^{2}}=\frac{2 \cdot 10^{14}}{\sqrt{3} \cdot \lambda_{c}^{2} \cdot U^{2}}$

The experimental values of the porosity and pore density that were calculated for the electrolytes that were used in this study are listed in Table 1 . They show that the porosity and pore density of the membranes formed in the phosphoric acid solution are slightly higher than those obtained for the oxalic acid and sulfuric acid solutions. The porosity of the alumina samples that were produced only in the sulfuric acid solution was close to the literature value of $10 \%$. Additionally, the porous anodic alumina films that had been fabricated in the oxalic acid from the high purity $\mathrm{Al}$ had a higher degree of pore order and, consequently, a better packed network of the pores compared to the Al1050 alloy. These results are in good agreement with the literature data [42].

The thickness of the anodic layer that had grown was estimated for both the substrate materials and various process durations from the FE-SEM cross-sectional views of the porous oxide layers, which had been taken for the samples that had been anodized in the sulfuric acid, oxalic acid and phosphoric acid solutions (Fig. 6).

It is clearly visible that the rate of the growth of the alumina layer was dependent on the type of electrolyte and temperature. A distinct increase in the oxide growth rate was recorded when the anodization was performed in the sulfuric acid solution, while the lowest growth rate was

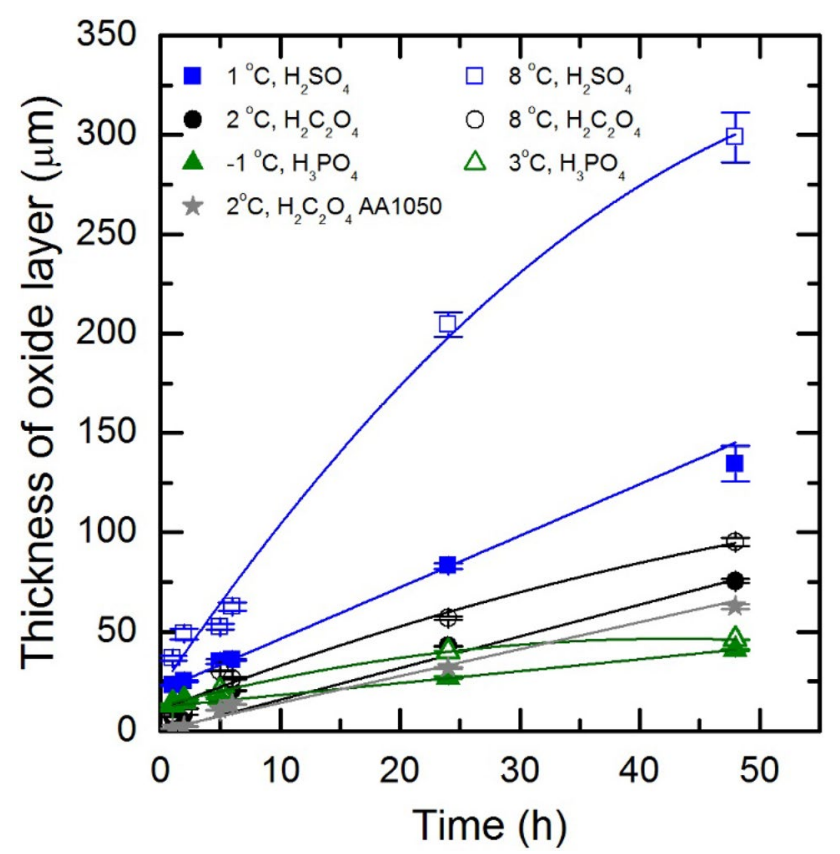

Fig. 6 The dependence between the thickness of the oxide layer and the duration of the second anodization step in $0.3 \mathrm{M} \mathrm{H}_{2} \mathrm{SO}_{4}, 0.3 \mathrm{M}$ $\mathrm{H}_{2} \mathrm{C}_{2} \mathrm{O}_{4}$ and $0.17 \mathrm{M} \mathrm{H}_{3} \mathrm{PO}_{4}$ at the different temperatures observed for the phosphoric acid solution. Moreover, the data that is presented in Fig. 6; Table 1 indicate that the rates of anodic oxide growth were higher for the high purity aluminum substrate than for the AA1050 alloy. The lower rate of the growth of the alumina layer on the AA1050 alloy can be attributed to the presence of the alloying elements. For the higher temperatures of the anodization process, there was a higher formation rate of the alumina layer regardless of the electrolyte that was used. Besides, with an increasing duration of the anodization, there was a curvilinear increase of the thickness of the oxide layer at higher temperatures for all of the electrolytes in the studied time range. The process of oxide growth on aluminum was studied by Zarazka et al. [43], however, for a shorter period time and at much higher temperatures. A porous alumina layer was fabricated during a two-step anodization process at $20{ }^{\circ} \mathrm{C}$ and $1{ }^{\circ} \mathrm{C}$ and the linear relationships between the thickness of the oxide layer and anodizing time were obtained. However, this study was carried out for an extended time (up to $50 \mathrm{~h}$ ) and indicated a non-linear increase in the thickness of the alumina layer. At higher temperatures, the oxide growth rate decreased with a longer duration of the process (more than $40 \mathrm{~h}$ ) in most cases. This behavior can be explained by the diffusion limited of aluminum oxidation at the bottom of the pores on the one hand. For the prolonged anodization, the oxide layer was thick, and the that was time required for the diffusion of the reactant species over the entire pore length was much longer. Therefore, when the porous layer grew, the diffusion of the electrolytes to the pore bottoms became more difficult, and the process of oxide formation slowed down. In addition, the anodization process was accompanied by a secondary dissolution of the alumina on the electrolyte/oxide interface due to the interaction of the oxide with the acid electrolyte (Eq. 5).

$\mathrm{Al}_{2} \mathrm{O}_{3}+6 \mathrm{H}_{(a q)}^{+} \rightarrow 2 \mathrm{Al}_{(a q)}^{3+}+3 \mathrm{H}_{2} \mathrm{O}$

At higher temperatures, the rate of the alumina dissolution was also higher. The growth of the porous alumina layer of a combination of two competitive concurrent processes, i.e. electrochemical oxide formation and secondary dissolution of the oxide layer.

A chemical treatment after the second anodizing process, is a very important stage for obtaining the membranes that are to be used as templates to produce of nanowires. Chemical etching was used to obtain larger pore diameters. This was done by immersing the samples in the acid solutions that had been used in the anodizing step, for a short time at a temperature of $30{ }^{\circ} \mathrm{C}$. The next stage of the membrane preparation is to widen the pores. It should be mentioned that the speed of pore widening depends on the type of electrolyte and the anodizing conditions, especially the anodizing voltage and temperature that are used. 
Figure 7 shows the SEM images of the top view of the AAO layer that was formed by anodizing of the high-purity Al substrate in the phosphoric acid under $180 \mathrm{~V}$ at $-1{ }^{\circ} \mathrm{C}$. The duration of the first and second anodizing steps were 2 and $10 \mathrm{~h}$, respectively. The pore widening procedure was performed using with the same electrolyte as the one that had been used in the anodizing process at $30{ }^{\circ} \mathrm{C}$. The relationships between the pore widening time and the uniformity of the pore diameter were found. The initially after anodization process formed oxide layers exhibit significantly
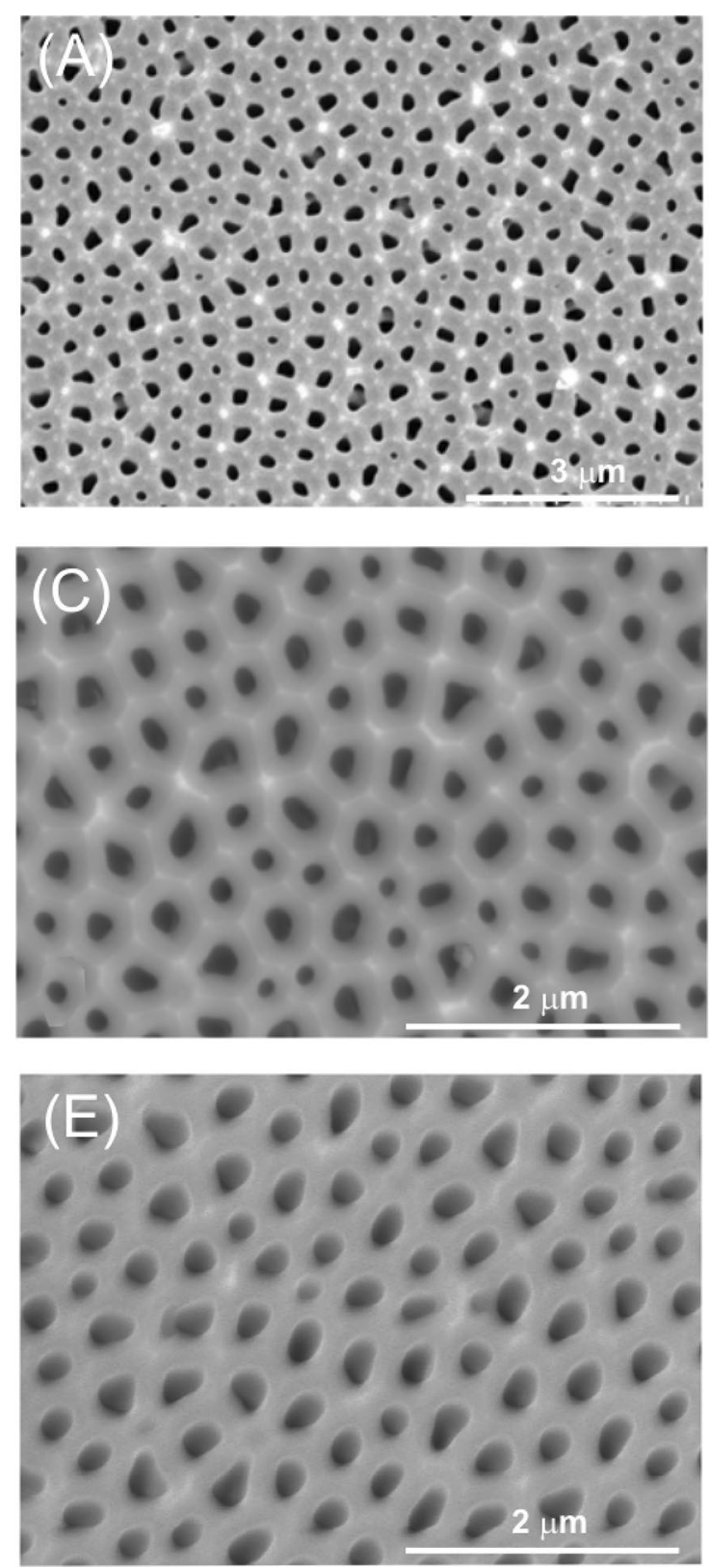

Fig. 7 SEM top view images of the porous alumina after the second anodization step in the $0.17 \mathrm{M}$ phosphoric acid solution under $180 \mathrm{~V}$ on the aluminum high purity Al substrate (a) and after the pore wid- different pore diameters and a lack of a distinct hexagonal pore ordered (Fig. 7a). After 120 min of chemical treatment in a phosphoric acid solution, uniformity in pore diameter was observed (Fig. 7d). For the pore widening time of $180 \mathrm{~min}$, an over fourfold increase in porosity was observed for both phosphoric, sulfuric and oxalic acid solutions (Table 2).

The pore diameters of the membranes were determined based on the SEM images using the ImageJ software. The results are presented in Table 2 and in Fig. 8. The wall
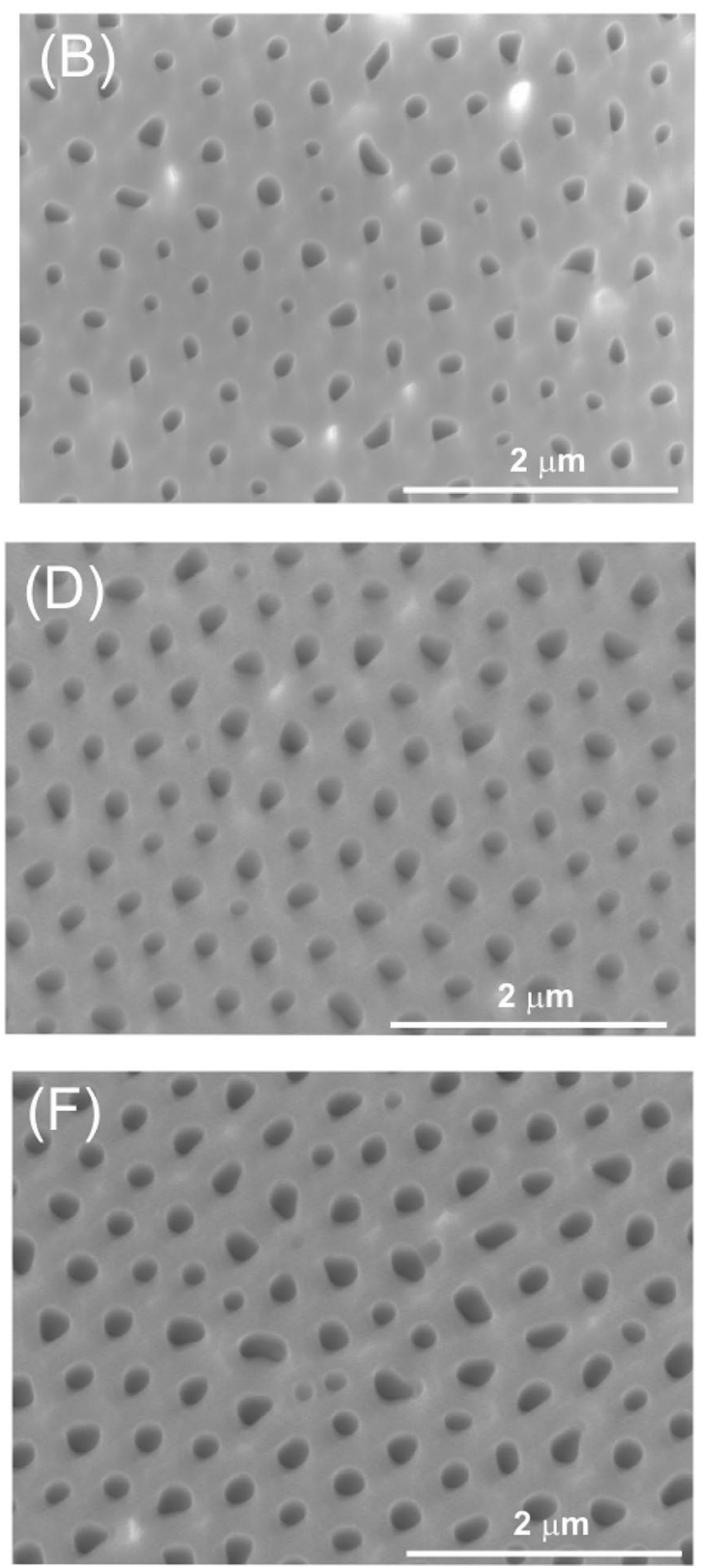

ening, which was performed in $0.17 \mathrm{M} \mathrm{H}_{3} \mathrm{PO}_{4}$ at $30{ }^{\circ} \mathrm{C}$. The duration of the pore openings was $30 \mathrm{~min}(\mathbf{b}), 60 \mathrm{~min}(\mathbf{c}), 90 \mathrm{~min}(\mathbf{d}), 120 \mathrm{~min}$ (e) and $150 \mathrm{~min}(\mathbf{f})$ 
Table 2 Experimental parameters and structural features of nanoporous alumina layer in chemical treatment process, where: $\mathrm{V}_{\mathrm{w}}-$ pore widening rate, $\mathrm{t}$ - pore widening time, $\mathrm{D}_{\mathrm{p}}$ - pore diameter, $\mathrm{D}_{\mathrm{c}}$-interpore distance, $\mathrm{W}$ - wall thickness, $\delta$ - porosity

\begin{tabular}{|c|c|c|c|c|c|c|c|c|c|c|c|c|c|c|c|}
\hline \multirow{3}{*}{$\begin{array}{l}\mathrm{t} \\
(\min )\end{array}$} & \multicolumn{15}{|c|}{ Electrolyte } \\
\hline & \multicolumn{5}{|c|}{$0.3 \mathrm{M} \mathrm{H}_{2} \mathrm{SO}_{4}$} & \multicolumn{5}{|c|}{$0.3 \mathrm{M} \mathrm{H}_{2} \mathrm{C}_{2} \mathrm{O}_{4}$} & \multicolumn{5}{|c|}{$0.17 \mathrm{M} \mathrm{H}_{3} \mathrm{PO}_{4}$} \\
\hline & $\begin{array}{l}\mathrm{D}_{\mathrm{p}} \\
\mathrm{nm}\end{array}$ & $\begin{array}{l}\mathrm{D}_{\mathrm{c}} \\
\mathrm{nm}\end{array}$ & $\begin{array}{l}\mathrm{W} \\
\mathrm{nm}\end{array}$ & $\begin{array}{l}\delta \\
\%\end{array}$ & $\begin{array}{l}\mathrm{V}_{\mathrm{w}} \\
\mathrm{nm} \min ^{-1}\end{array}$ & $\begin{array}{l}\mathrm{D}_{\mathrm{p}} \\
\mathrm{nm}\end{array}$ & $\begin{array}{l}\mathrm{D}_{\mathrm{c}} \\
\mathrm{nm}\end{array}$ & $\begin{array}{l}\mathrm{W} \\
\mathrm{nm}\end{array}$ & $\begin{array}{l}\delta \\
\%\end{array}$ & $\begin{array}{l}\mathrm{V}_{\mathrm{w}} \\
\mathrm{nm} \min ^{-1}\end{array}$ & $\begin{array}{l}\mathrm{D}_{\mathrm{p}} \\
\mathrm{nm}\end{array}$ & $\begin{array}{l}\mathrm{D}_{\mathrm{c}} \\
\mathrm{nm}\end{array}$ & $\begin{array}{l}\mathrm{W} \\
\mathrm{nm}\end{array}$ & $\begin{array}{l}\delta \\
\%\end{array}$ & $\begin{array}{l}\mathrm{V}_{\mathrm{w}} \\
\mathrm{nm} \min ^{-1}\end{array}$ \\
\hline 0 & $18 \pm 4$ & $66 \pm 4$ & 24.0 & 7 & $0.38 \pm 0.15$ & $30 \pm 5$ & $99 \pm 17$ & 34.5 & 8 & $0.68 \pm 0.29$ & $105 \pm 12$ & $425 \pm 98$ & 160.0 & 6 & $2.41 \pm 1.28$ \\
\hline 30 & $20 \pm 7$ & & 23.0 & 8 & & $37 \pm 9$ & & 31.0 & 13 & & $152 \pm 32$ & & 136.5 & 12 & \\
\hline 60 & $28 \pm 5$ & & 19.0 & 16 & & $50 \pm 4$ & & 24.5 & 23 & & $164 \pm 17$ & & 130.5 & 13 & \\
\hline 90 & $33 \pm 5$ & & 16.5 & 23 & & $60 \pm 9$ & & 19.5 & 33 & & $201 \pm 24$ & & 112.0 & 20 & \\
\hline 120 & $36 \pm 6$ & & 15.0 & 27 & & $65 \pm 3$ & & 17.0 & 39 & & $204 \pm 17$ & & 110.5 & 21 & \\
\hline 150 & $38 \pm 4$ & & 14.0 & 30 & & $65 \pm 6$ & & 17.0 & 39 & & $218 \pm 23$ & & 103.5 & 24 & \\
\hline 180 & $39 \pm 4$ & & 13.5 & 32 & & $65 \pm 4$ & & 17.0 & 39 & & $232 \pm 15$ & & 96.5 & 27 & \\
\hline
\end{tabular}

thickness (W) of the pores for the perfect hexagonal arrangement can be given as follows:

$W=\frac{D_{c}-D_{p}}{2}$

The results indicated that the duration of the chemical treatment and the electrolyte type significantly affect the

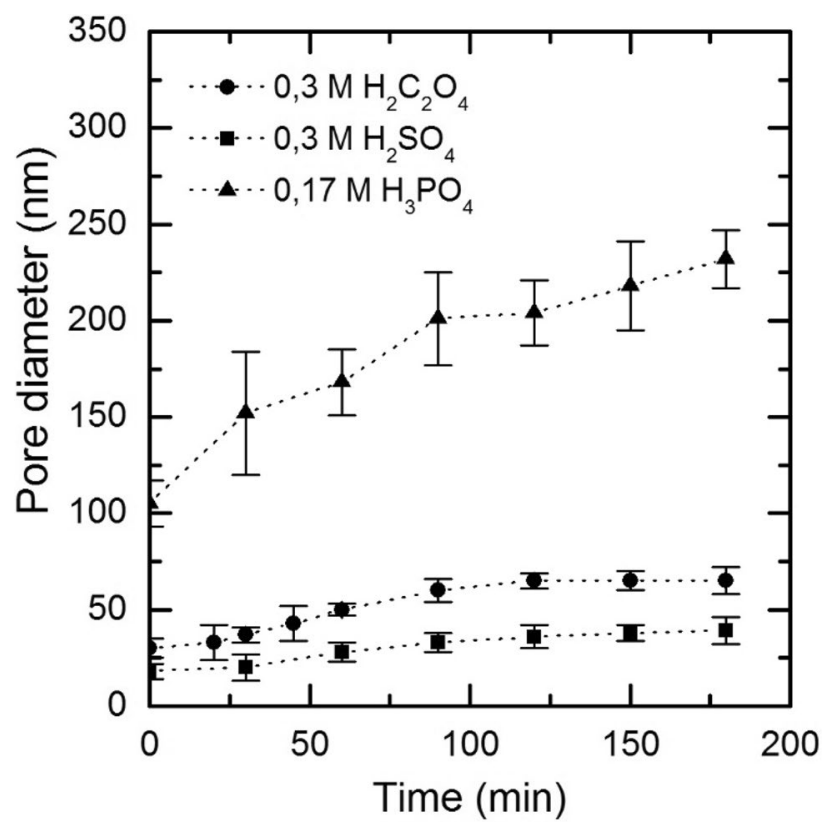

Fig. 8 The effect of the pore widening time on the pore diameter for the alumina layer that had been obtained via anodization in the $0.3 \mathrm{M}$ sulfuric acid, 0.3 $\mathrm{M}$ oxalic acid and $0.17 \mathrm{M}$ phosphoric acid solutions. The pore widening was performed in the acid solutions in which the anodic oxidation had been performed at a temperature of $30{ }^{\circ} \mathrm{C}$ pore diameter. When the duration of the pore widening in phosphoric acid solution was extended to $180 \mathrm{~min}$, the average pore diameter increased to about $230 \mathrm{~nm}$ (Table 2; Fig. 8). For the sulfuric and oxalic acid solutions, the pore diameters increase with a widening time of about $120 \mathrm{~min}$, while above this time, $D_{p}$ remains constant. Notice, that after the second anodizing step, the nanochannels in the anodic alumina layer had their own starting diameter, which increased during the pore widening process. Furthermore, the rate of pore widening was also related to their size. For pores with larger diameters, the electrolyte diffusion into them was easier and the solution dissolved the oxide walls more quickly. The greatest pore widening was observed in the phosphoric acid solution, while the increase in the pore diameter during the chemical treatment in sulfuric acid and oxalic acid solutions was comparable.

After the pores were widened, the Al substrate was removed in $0.2 \mathrm{M} \mathrm{HCl}$ and $0.1 \mathrm{M} \mathrm{CuCl}_{2}$ solution. Despite this, the bottom of the pores was still closed by the barrier layer. Therefore, the last step of the through-hole membrane preparation was pore opening (and simultaneous widening) which was performed in a phosphoric acid solution. Importantly, the thickness of the barrier layer was not the same for all of the AAO membranes and was dependent on the type of electrolyte and the anodizing conditions, primarily the applied voltage. The etching rate of the alumina membrane strongly depended on the concentration of the phosphoric acid solution and the temperature. Because that the thickness of the AAO barrier layers obtained in the sulfuric and oxalic acid solutions were smaller than in the phosphoric acid, acid solutions at two different concentrations were used to open the pores. Therefore, the oxide samples that had been obtained in the sulfuric and oxalic acid solutions were chemically etched in $5 \% \mathrm{H}_{3} \mathrm{PO}_{4}$, while the samples that had been obtained in the phosphoric acid were etched in $10 \%$ $\mathrm{H}_{3} \mathrm{PO}_{4}$. The membranes that had been prepared in this way 
were used to produce the $\mathrm{Co}, \mathrm{Fe}$ and $\mathrm{CoFe}$ nanowires in the next stage of the study $[5,32,44]$.

\section{Conclusion}

Specimens of high purity aluminum were anodized in $0.3 \mathrm{M}$ sulfuric, $0.3 \mathrm{M}$ oxalic and $0.17 \mathrm{M}$ phosphoric acid solutions while the AA1050 alloy samples were anodized in a $0.3 \mathrm{M}$ oxalic acid solution. The regularity of the pore arrangement and structural features of the AAO membranes that had been formed by two-step anodization under various electrolysis voltages and temperatures for the three electrolytes were compared. The following conclusions were drawn:

- The presence of the alloying elements in the AA1050 alloy affects the microstructure of the anodic oxide films, which causes the formation of cracks and defects on the alloy surface together with a branching and discontinuity of the pores.

- The rate of oxide growth, pore diameter, porosity and pore density of the oxide layers that are formed from the AA1050 alloy are smaller while the interpore distance and wall thickness are larger than those that are obtained for high purity aluminum.

- The rate of oxide growth depends on the type of electrolyte - the highest growth rates were observed for anodizing in the sulfuric acid, whereas the lowest growth rates were recorded for phosphoric acid.

- The rate of oxide growth depends on the temperaturethe highest oxide growth rates were observed at higher temperatures.

- During the chemical treatment of the oxide films in the sulfuric and oxalic acid solutions, the pore diameter increases with the pore widening time to about $120 \mathrm{~min}$ after which $\mathrm{D}_{\mathrm{p}}$ remains constant. In turn, for the phosphoric acid solution, the pore diameter increases in the studied time range.

Acknowledgements This research was partially supported by the AGH University of Science and Technology (No. 16.16.180.006)

Open Access This article is licensed under a Creative Commons Attribution 4.0 International License, which permits use, sharing, adaptation, distribution and reproduction in any medium or format, as long as you give appropriate credit to the original author(s) and the source, provide a link to the Creative Commons licence, and indicate if changes were made. The images or other third party material in this article are included in the article's Creative Commons licence, unless indicated otherwise in a credit line to the material. If material is not included in the article's Creative Commons licence and your intended use is not permitted by statutory regulation or exceeds the permitted use, you will need to obtain permission directly from the copyright holder. To view a copy of this licence, visit http://creativecommons.org/licenses/by/4.0/.

\section{References}

1. A. Sugawara, D. Streblechenko, M. McCartneq, M.R. Scheinfein, IEEE Trans. Magn. 34, 1081 (1998)

2. D. Routkevitch, A.A. Tager, J. Haruyama, D. Almawlawi, M. Moskovits, J.M. Xu, IEEE Trans. Electron. Devices 43, 1646 (1996)

3. Y. Cui, C.M. Lieber, Science 291(1), 851 (2001)

4. P.S. Fodor, G.M. Tsoi, L.E. Wenger, J. Appl. Phys. 91, 8186 (2002)

5. I. Dobosz, W. Gumowska, M. Uhlemann, J.A. Koza, Arch. Metall. Mater. 55, 683 (2010)

6. K. Tsukagoshi, B.W. Alphenaar, M. Wagner, Mater. Sci. Eng. B 84, 26 (2001)

7. V.V. Kulish, P.M. Tomchuk, Surf. Sci. 602, 1045 (2008)

8. Y.I. Lee, N.V. Myung, Y.H. Choa, Scr. Mater. 68, 463 (2013)

9. Z. Lei, X. Liu, R. Li, H. Wang, Y. Wu, Z. Lu, Scr. Mater. 146, 340 (2018)

10. T. Gao, J.C. Fan, G.W. Meng, Z.Q. Chu, L.D. Zhang, Thin Solid Films 401, 102 (2001)

11. Q. Wang, Z.T. Song, W.L. Liu, C.L. Lin, T.H. Wang, Appl. Surf. Sci. 230, 8 (2004)

12. Y.N. Wang, F.X. Jiang, L.J. Yan, X.H. Xu, Appl. Surf. Sci. 441, 415 (2018)

13. M. Vorozhtsova, J. Drbohlavova, J. Hubalek, in Microsensors. ed. by I. Minin (IntechOpen, London, 2011), p. 3049

14. G.E.J. Poinern, N. Ali, D. Fawcett, Materials 4, 487 (2011)

15. W. Lee, J. Mater. 62, 57 (2010)

16. Z. Wua, C. Richterb, L. Menon, J. Electrochem. Soc. 154, E8 (2007)

17. A.N. Pickett, Electrospinning Applications in Mechanochemistry and Multifunctional Hydrogel Materials (University of Illinois at Urbana-Champaign, Champaign, 2012).

18. H. Masuda, A. Abe, M. Nakao, A. Yokoo, T. Tamamura, K. Nishio, Adv. Mater. 15, 161 (2003)

19. J. Choi, R.B. Wehrspohn, U. Gösele, Adv. Mater. 15, 1531 (2003)

20. G.D. Sulka, S. Stroobants, V. Moshchalkov, G. Borghs, J.-P. Celis, J. Electrochem. Soc. 149, 97 (2002)

21. H. Masuda, F. Hasegwa, S. Ono, J. Electrochem. Soc. 144, L127 (1997)

22. Q. Ji, Y. Chen, L. Ji, X. Jiang, K.-N. Leung, Microelectron. Eng. 83, 796 (2006)

23. H. Masuda, K. Fukuda, Science 268, 1466 (1995)

24. J.P. O'Sullivan, G.C. Wood, Proc. R. Soc. A. 317, 511 (1970)

25. F. Keller, M.S. Hunter, D.L. Robinson, J. Electrochem. Soc. 100, 411 (1953)

26. H. Masuda, K. Yada, A. Osaka, Jpn. J. Appl. Phys. 37, L1340 (1998)

27. G.D. Sulka, K.G. Parkoła, Electrochim. Acta 52, 1880 (2007)

28. K. Nielsch, J. Choi, K. Schwirn, R.B. Wehrspohn, U. Gösele, Nano Lett. 2, 677 (2002)

29. O. Jessensky, F. Müller, U. Gösele, Appl. Phys. Lett. 72, 1173 (1998)

30. W.J. Stępniowski, Z. Bojar, Surf. Coat. Tech. 206, 265 (2011)

31. G.D. Sulka, A. Brzózka, L. Zaraska, M. Jaskuła, Electrochim. Acta 55, 4368 (2010)

32. W. Gumowska, I. Dobosz, B. Wrzoszczyk, Arch. Metall. Mater. 59, 137 (2014)

33. Y. Ma, Y. Wen, J. Li, Y. Li, Z. Zhang, C. Feng, R. Sun, Sci Rep 6, 1-8 (2016)

34. Y. Shang, L. Wang, D. Niu, Z. Liu, Y. Wang, C. Liu, J. Electrochem. Sci. 11, 1549 (2016)

35. A.P. Li, F. Müller, A. Birner, K. Nielsch, U. Gösele, J. Appl. Phys. 84, 6023 (1998) 
36. F. Li, L. Zhang, R.M. Metzger, Chem. Mater. 10, 2470 (1998)

37. S. Ono, N. Masuko, Surf. Coat. Tech. 169-170, 139 (2003)

38. S. Ono, M. Saito, M. Ishiguro, H. Asoh, J. Electrochem. Soc. 151, B473 (2004)

39. I. Horcas, R. Fernández, J.M. Gómez-Rodriguez, J. Colchero, J. Gómez-Herrero, A.M. Baro, Rev. Sci. Instrum. 78, 013705 (2007)

40. National Institute of Mental Health, ImageJ (National Institute of Mental Health, Bethesda, 2012).

41. G.D. Sulka, K.G. Parkoła, Thin Solid Films 515, 338 (2006)

42. L. Zarazka, G.D. Sulka, J. Szeremeta, M. Jaskuła, Electrochim. Acta 55, 4377 (2010)
43. L. Zarazka, G.D. Sulka, M. Jaskuła, J. Solid State Electrochem. 15, $2427(2011)$

44. I. Dobosz, W. Gumowska, M. Czapkiewicz, J. Solid State Electrochem. 18, 2963 (2014)

Publisher's Note Springer Nature remains neutral with regard to jurisdictional claims in published maps and institutional affiliations. 